\title{
Molecular Characterization of Pyraclostrobin Resistance and Structural Diversity of the Cytochrome $b$ Gene in Botrytis cinerea from Apple
}

\author{
Y. N. Yin, Y. K. Kim, and C. L. Xiao
}

First author: Department of Plant Pathology, Washington State University, Tree Fruit Research and Extension Center, Wenatchee 98801, and Institute of Biotechnology, Zhejiang University, Hangzhou, China; and second and third authors: Department of Plant Pathology, Washington State University, Tree Fruit Research and Extension Center, Wenatchee.

Current address of C. L. Xiao: United States Department of Agriculture-Agricultural Research Service, San Joaquin Valley Agricultural Sciences Center, Parlier, CA 93648.

Accepted for publication 10 November 2011.

\begin{abstract}
Yin, Y. N., Kim, Y. K., and Xiao, C. L. 2012. Molecular characterization of pyraclostrobin resistance and structural diversity of the cytochrome $b$ gene in Botrytis cinerea from apple. Phytopathology 102:315-322.

Botrytis cinerea isolates obtained from apple orchards were screened for resistance to the quinone outside inhibitor (QoI) pyraclostrobin. Of the 220 isolates tested, $43(19.5 \%)$ were resistant to pyraclostrobin. Analysis of partial sequences of the cytochrome $b$ gene (cyt $b$ ) in five pyraclostrobin-resistant (PR) and five pyraclostrobin-sensitive (PS) isolates showed that PR isolates harbored the point mutation leading to the substitution of glycine by alanine at codon position 143 in $c y t b$ (G143A). Two pairs of allele-specific primers were designed based on this point mutation, and allele-specific polymerase chain reaction analysis with these primers showed that all $73 \mathrm{PR}$ isolates (including 30 collected from decayed apple fruit) harbored the G143A mutation but PS isolates did not. Six pairs of primers were designed to analyze the presence of various introns in $c y t b$. There were six types (I to VI) of $c y t b$ present in 247

four introns (Bcbi-67/68, Bcbi-131/132, Bcbi-143/144, and Bcbi-164), 176 had type II cyt $b$ containing three introns (Bcbi-67/68, Bcbi-131/132, and Bcbi-164), six had type III $c y t b$ containing two introns (Bcbi-67/68 and Bcbi-131/132), one had type IV cyt $b$ containing two introns (Bcbi$131 / 132$ and Bcbi-164), one had type $\mathrm{V} c y t b$ containing only the Bcbi$131 / 132$ intron, and 40 had type VI $c y t b$ containing no introns. This is the first report of types III to VI cyt $b$ present in $B$. cinerea. All 73 PR isolates did not carry the Bcbi-143/144 intron in $c y t b$. Of the 247 isolates tested, $>90 \%$ did not carry the Bcbi-143/144 intron in $c y t b$, suggesting that $B$. cinerea populations from apple pose a high inherent risk for the development of resistance to QoIs because the presence of this intron in $c y t b$ prevents the occurrence of G143A-mediated resistance. Analysis of genetic background based on three microsatellite primers showed that PR isolates originated from different lineages, and there was no correlation between cyt $b$ types (I, II, and III) and the genetic background of the isolates; however, isolates carrying type VI cyt $b$ might originate from the same lineage.
\end{abstract} isolates of $B$. cinerea collected from various apple-production areas in Washington State. Of the 247 isolates, 23 had type I cyt $b$ containing all
Additional keywords: fungicide resistance, gray mold.
Botrytis cinerea Pers. (teleomorph Botryotinia fuckeliana (de Bary) Whetzel) infects a broad range of economically important plant species, including vegetables, fruit, and ornamental plants, and may cause diseases in the field or after harvest, depending on crop species (15). Control of diseases caused by Botrytis cinerea is largely dependent on the use of synthetic fungicides (22). However, $B$. cinerea is a high-risk fungal pathogen in the development of fungicide resistance because of its short life cycle and prolific reproduction (3). Management of fungicide resistance is important to the chemical control of diseases caused by $B$. cinerea (22). In apple, gray mold caused by $B$. cinerea is a major postharvest fruit rot disease. Preharvest application of Pristine (a recently registered premixed formulation of pyraclostrobin and boscalid) is effective for controlling gray mold in stored apples, and this practice has been increasingly implemented by apple growers and packers in the Pacific Northwest since the registration of Pristine in 2005 (33). However, resistance to pyraclostrobin was observed in $B$. cinerea isolates obtained from gray mold-decayed fruit originating from apple orchards where Pristine had been used for 4 years since 2005 (18).

Corresponding author: C. L. Xiao; E-mail address: Chang-Lin.Xiao@ars.usda.gov

http://dx.doi.org/10.1094/PHYTO-08-11-0234

(c) 2012 The American Phytopathological Society
Pyraclostrobin belongs to the quinone outside inhibitor (QoI) class of fungicides, which inhibit mitochondrial respiration at the ubiquinol oxidation center site of the cytochrome $b c_{1}$ enzyme complex, and QoIs are effective in controlling a wide range of plant diseases (2). QoIs are single-site mode-of-action fungicides and are considered to pose high risk for the development of resistance in fungal pathogens (8). To date, many phytopathogenic fungi have developed resistance to QoIs $(1,2,9,16)$. In most cases, the point mutation at codon 143 in the cytochrome $b$ gene (cyt $b$ ) resulting in the substitution of glycine by alanine (G143A) confers resistance to QoIs (6), and field isolates harboring the G143A mutation in various fungal pathogens exhibit high levels of resistance to QoI fungicides (10). Point mutations F129L and G137R in $c y t b$ conferring resistance to QoIs have also been observed in several fungal pathogens such as Pythium aphanidermatum (12), Pyricularia grisea (20), Alternaria solani, Plasmopara viticola, Pyrenophora teres, and P. tritici-repentis (30), but these mutations result in low levels of resistance (10). In field isolates of $B$. cinerea from grape, strawberry, and vegetables, the mutation G143A has been reported to be correlated with resistance to QoIs $(1,14,16,23)$.

Sequence analysis of $c y t b$ from several plant-pathogenic fungi indicated the presence of varying numbers of introns in $c y t b$ among these fungi $(12,32)$. Variation in the arrangement of exons and introns has also been observed between different species in 
the same genus (7). For example, $P$. teres contained three introns between amino acid positions 131 to 163 , while $P$. tritici-repentis contained two introns in the same region. Similar differences in cyt $b$ structure have been reported in A. solani versus A. alternata (30). Mitochondrial $c y t b$ in fungi has group-I introns, which are self-splicing RNAs (4). The exonic sequence near the splice junction plays an essential role in mRNA splicing and subsequent gene transcription $(5,21)$. The presence of an intron directly after codon 143 for glycine has been found only in isolates sensitive to QoIs in these pathogens, and it is believed that the presence of the intron between 143 and 144 codons prevents the occurrence of point mutation at this codon (13). Thus, the inherent risk for development of QoI resistance in a pathogen can be assessed based on the frequency of isolates carrying the intron between 143 and 144 codons in cyt $b$. In $B$. cinerea, Banno et al. (1) reported there were two types of $c y t b$ (i.e., with or without the intron between codons 143 and 144, designated as the Bcbi-143/144 intron). The Bcbi-143/144 intron only occurred in QoI-sensitive isolates of $B$. cinerea $(1,14,16,23)$.

Resistance to pyraclostrobin is emerging in B. cinerea populations in apple orchards where the fungicide has been used; therefore, it would be prudent to assess the potential inherent risk in the development of QoI resistance in the fungal populations from apple based on the frequency of the presence of the Bcbi$143 / 144$ intron in $c y t b$ in the populations. Currently, little information is available as to the variation in the genomic structure of $c y t b$ in $B$. cinerea $(1,23)$. Such information is important to further understanding of molecular mechanisms of QoI resistance in $B$. cinerea and to the development of molecular assays for detection of the G143A mutation in the pathogen populations.

The objectives of this study were to (i) estimate the frequency of pryaclostrobin-resistant isolates in $B$. cinerea populations in apple orchards; (ii) characterize the structure of the $c y t b$ gene in $B$. cinerea, determine whether mutations in cyt $b$ correlate with pyraclostrobin resistance, and develop polymerase chain reaction (PCR) assays for detection of pyraclostrobin resistance in $B$. cinerea; (iii) detect the presence of the Bcbi-143/144 intron in cyt $b$ to assess the inherent risk for the development of QoI resistance in $B$. cinerea populations; and (iv) assess genetic relationships between pyraclostrobin-resistant and -sensitive (PR and PS, respectively) isolates of $B$. cinerea from apple.

\section{MATERIALS AND METHODS}

Frequency of pyraclostrobin resistance in apple orchards. To monitor pyraclostobin resistance in apple orchards, symptomless 'Gala' apple fruit were sampled in August and September 2009 from five conventional apple orchards located in Brewster, WA. In these orchards, the pyraclostrobin-containing fungicide Pristine had been used in each of the last four consecutive years, and $B$. cinerea isolates were obtained from floral parts and stems of apple fruit following the procedure described previously in a parallel study on boscalid resistance in B. cinerea (34). In total, 220 single-spore isolates of $B$. cinerea were obtained from the five orchards. Isolates were stored as mycelial plugs in $15 \%$ glycerol at $-80^{\circ} \mathrm{C}$.

Technical-grade pyraclostrobin (98\% active ingredient [a.i.]; BASF Corporation, Research Triangle Park, NC) was dissolved in $100 \%$ acetone to produce a stock solution containing $100 \mathrm{mg} / \mathrm{ml}$. To screen pyraclostrobin resistance in $220 \mathrm{~B}$. cinerea isolates, sensitivity of mycelial growth to pyraclostrobin was tested on potato dextrose agar (PDA) amended with pyraclostrobin at the discriminatory concentration of $5 \mu \mathrm{g} / \mathrm{ml}$ plus salicylhydroxamic acid (99\% a.i.; Sigma-Aldrich, St. Louis) at $100 \mu \mathrm{g} / \mathrm{ml}$ to inhibit the alternative oxidase respiration (27) following the procedure described previously (18). Isolates that were able to grow on the amended PDA were designated as PR isolates. Isolates that were unable to grow on the amended PDA were designated as PS isolates. The experiment was conducted twice for all isolates and one additional test was performed for resistant isolates. The concentration of pyraclostrobin resulting in 50\% inhibition of mycelial growth relative to the control $\left(\mathrm{EC}_{50}\right)$ for each $\mathrm{PR}$ isolate was determined following the procedure of Kim and Xiao (18).

Phenotypes of isolates used for characterization of QoI resistance. In total, 247 (73 PR and $174 \mathrm{PS}$ ) $B$. cinerea isolates were included in this study (Table 1). Of these isolates, $43 \mathrm{PR}$ and 53 PS isolates were chosen from the 220 single-spore isolates obtained from the five apple orchards as described above; 30 PR and 35 PS isolates were obtained during 2007-09 from gray mold-decayed apple fruit sampled from a fruit packinghouse as described previously (19); and 86 PS isolates were recovered during 2001-03 from either decayed apple fruit sampled from fruit packinghouses or floral parts of apple fruit sampled from apple orchards located in the Okanogan, Columbia Basin, Wenatchee, and Yakima areas in Washington State, and these isolates were previously used in the pyraclostrobin-baseline sensitivity study (18). Isolates were stored as mycelial plugs in $15 \%$ glycerol at $-80^{\circ} \mathrm{C}$ prior to reactivation for use in this study. $\mathrm{EC}_{50}$ values of pyraclostrobin for the PR isolates obtained from decayed apple fruit sampled from a fruit packinghouse were determined in a mycelial growth assay as previously described (18). In the baseline sensitivity study described previously, the mean $\mathrm{EC}_{50}$ of pyraclostrobin for sensitive isolates of $B$. cinerea from apple was $0.043 \mu \mathrm{g} / \mathrm{ml}$ (18). Resistance factor (RF; folds of $\mathrm{EC}_{50}$ for a resistant isolate relative to the mean $\mathrm{EC}_{50}$ for the sensitive isolates in the baseline) for each PR isolate was calculated. PR isolates with $\mathrm{RF}>100$ were considered highly resistant to pyraclostrobin (10).

DNA extraction and sequencing. Genomic DNA of $B$. cinerea was extracted from mycelium cultured on PDA using the FastDNA kit and the FastPrep instrument (MP Biomedicals,

TABLE 1. Frequency of Botrytis cinerea isolates carrying different types of cytochrome $b$ gene $(c y t b)$ collected from four main apple-producing regions in Washington State

\begin{tabular}{|c|c|c|c|c|c|c|c|c|}
\hline \multirow[b]{2}{*}{ Region } & \multirow[b]{2}{*}{ Phenotype $^{\mathrm{a}}$} & \multirow[b]{2}{*}{ Number of isolates } & \multicolumn{6}{|c|}{ Number of isolates carrying the $c y t b$ gene $^{\mathrm{b}}$} \\
\hline & & & Type I & Type II & Type III & Type IV & Type V & Type VI \\
\hline Okanogan & $\mathrm{R}$ & 65 & 0 & 64 & 0 & 0 & 0 & 1 \\
\hline Columbia Basin & S & 39 & 2 & 33 & 1 & 0 & 0 & 3 \\
\hline \multirow[t]{2}{*}{ Wenatchee } & $\mathrm{R}$ & 0 & 0 & 0 & 0 & 0 & 0 & 0 \\
\hline & $\mathrm{S}$ & 22 & 3 & 16 & 0 & 0 & 0 & 3 \\
\hline Total & $\ldots$ & 247 & 23 & 176 & 6 & 1 & 1 & 40 \\
\hline
\end{tabular}

${ }^{\mathrm{a}} \mathrm{R}$ and $\mathrm{S}=$ resistant and sensitive, respectively, to pyraclostrobin.

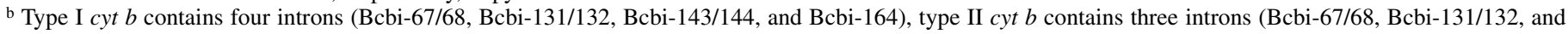
Bcbi-164), type III $c y t b$ contains two introns (Bcbi-67/68 and Bcbi-131/132), type IV $c y t b$ contains two introns (Bcbi-131/132 and Bcbi-164), type V $c y t b$ contains only the Bcbi-131/132 intron, and type VI cyt $b$ contains no introns. 
Irvine, CA) according to the manufacturer's instructions. Based on the sequence of the $c y t b$ gene of $B$. cinerea (GenBank accession number AB428335), the primer pair 129S-F + 129S-R was designed to amplify a partial fragment containing codon 129 in the $c y t b$ gene, and the prime pair $137 \mathrm{~S}-\mathrm{F}+137 \mathrm{~S}-\mathrm{R}$ was designed to amplify a partial fragment containing codons 137 and 143 in the cyt $b$ gene (Table 2). Five PR (8003, 8178, 8080, 8220, and $8134)$ and five PS $(6629,8018,8147,8210$, and 8246) isolates were sequenced with the primer pair $137 \mathrm{~S}-\mathrm{F}+137 \mathrm{~S}-\mathrm{R}$. PCR amplifications were performed in a $25-\mu \mathrm{l}$ volume containing $20 \mathrm{ng}$ of fungal genomic DNA, $0.2 \mu \mathrm{M}$ each primer, $0.2 \mathrm{mM}$ each dNTP (Promega Corp., Madison, WI), $1.5 \mathrm{mM} \mathrm{MgCl} 2,1 \times$ Promega Taq polymerase buffer (10 mM Tris-HCl, [pH 9.0], $50 \mathrm{mM} \mathrm{KCl}$, and $0.1 \%$ Triton X-100), and 1.5 units of Taq polymerase (Promega Corp.). PCR was carried out in an iCycler thermal cycler (BioRad Life Science Research Group, Hercules, CA) with the following parameters: an initial preheating for $3 \mathrm{~min}$ at $95^{\circ} \mathrm{C}$; followed by 35 cycles of denaturation at $94^{\circ} \mathrm{C}$ for $40 \mathrm{~s}$, annealing at $56^{\circ} \mathrm{C}$ for $40 \mathrm{~s}$, and extension at $72^{\circ} \mathrm{C}$ for $1.5 \mathrm{~min}$; and a final extension at $72^{\circ} \mathrm{C}$ for $5 \mathrm{~min}$. The PCR products were separated on $1.2 \%$ agarose gels in $1 \times$ Tris-acetate (TAE) buffer and photographed using a digital imaging system (Ultra Violet Products, Upland, CA) after staining with ethidium bromide. PCR products were purified using QIAquick Gel Extraction kit (Qiagen Inc., Chatsworth, CA) according to the manufacturer's instructions. Cycle sequencing was performed using the ABI Prism BigDye Terminator v3.1 Cycle Sequencing kit (Applied Biosystems, Foster City, CA) and PCR primers. The sequencing reaction mixture contained 0.5 to $1 \mu \mathrm{g}$ DNA, 3.2 pmol of primer, $4 \mu \mathrm{l}$ of BigDye Terminator Cycle Sequencing Ready Reaction Mix, and sterile distilled water in 10- $\mu$ l total volumes. Cycle sequencing was carried out at $96^{\circ} \mathrm{C}$ for $15 \mathrm{~s}, 50^{\circ} \mathrm{C}$ for $15 \mathrm{~s}$, and $60^{\circ} \mathrm{C}$ for 4 min for 25 cycles. Products were purified using Centriflex Gel Filtration Cartridges (Edge Biosystems, Gaithersburg, MD) and dried in a speed vacuum concentrator, and sequences were read in the Laboratory for Biotechnology and Bioanalysis, School of Molecular Biosciences, Washington State University, Pullman. Representative sequences were deposited in GenBank under accession numbers JF689846 to JF689847.

PCR assays for detection of the point mutation G143A. Comparing the $c y t b$ sequences in the five PR and five PS isolates, the point mutation G143A was observed only in the PR isolates. Based on the single point mutation from $\mathrm{G}$ to $\mathrm{C}$ at the codon position 143, a nucleotide $\mathrm{C}$ at the $3^{\prime}$ end of the forward primer $143-\mathrm{F}$ was designed to match the $\mathrm{C}$ at this codon position in $\mathrm{PR}$ isolates. Primers $143-\mathrm{F}+137 \mathrm{~S}-\mathrm{R}$ were expected to generate a 262-bp fragment only from PR isolates harboring the point mutation G143A, not from PS isolates. Specificity of this primer pair was tested with 73 PR and 50 PS isolates. PCR amplifications were performed as described above. PCR was carried out with the following parameters: an initial preheating for $3 \mathrm{~min}$ at $95^{\circ} \mathrm{C}$; followed by 35 cycles of denaturation at $94^{\circ} \mathrm{C}$ for $30 \mathrm{~s}$, annealing at $62^{\circ} \mathrm{C}$ for $30 \mathrm{~s}$, extension at $72^{\circ} \mathrm{C}$ for $30 \mathrm{~s}$; and terminated with a final extension at $72^{\circ} \mathrm{C}$ for $5 \mathrm{~min}$. The PCR products were analyzed on $1.2 \%$ agarose gels in $1 \times$ TAE buffer. Surveying this point mutation from all 73 PR isolates with primers $143-\mathrm{F}+$ 137S-R, 72 gave a single 262-bp band. One isolate, 7452, gave no PCR product and was further tested to determine whether there was a mutation at codon 129 or 137 using primer pairs $129 \mathrm{~S}-\mathrm{F}+$ 129S-R and 137S-F + 137S-R, respectively. There were still no amplifications. This finding led us to further examine the structure of $c y t b$.

Gene structure of $c y t \boldsymbol{b}$ in $\boldsymbol{B}$. cinerea from apple. Based on previous reports $(1,16)$, there are two groups of $c y t b$ in $B$. cinerea (with or without the Bcbi-143/144 intron) (Fig. 1). The primer pair $137 \mathrm{~S}-\mathrm{F}+137 \mathrm{~S}-\mathrm{R}$ was used to detect whether the Bcbi$143 / 144$ intron was present: isolates giving a 687 -bp product were identified as not containing the Bcbi-143/144 intron, whereas isolates giving a 1,892-bp product were identified as containing the Bcbi-143/144 intron. To test whether the Bcbi-143/144 intron was absent in PR isolates and the frequency of isolates carrying the Bcbi-143/144 intron within PS populations, 73 PR and 174 PS isolates were amplified with the primer pair $137 \mathrm{~S}-\mathrm{F}+137 \mathrm{~S}-\mathrm{R}$ but $1 \mathrm{PR}$ isolate (7452) and $46 \mathrm{PS}$ isolates gave no product.

To understand why these 47 isolates generated no amplifications with primer pair $137 \mathrm{~S}-\mathrm{F}+137 \mathrm{~S}-\mathrm{R}$, and why isolate 7452 also gave no product with the primer pair 129S-F + 129S-R, four pairs of primers (i.e., 1 int-F +1 int-R, 2 int-F +2 int-R, 3 int-F + 3 int-R, and 4 int-F +4 int-R) (Table 2) were designed to amplify the Bcbi-67/68, Bcbi-131/132, Bcbi-143/144, and Bcbi-164 introns, respectively. These four pairs of primers were designed based only on the exon sequence of the $c y t b$ gene of $B$. cinerea (GenBank accession number AB428335). PCR amplifications were performed as described above. PCR was carried out with the following parameters: an initial preheating for $3 \mathrm{~min}$ at $95^{\circ} \mathrm{C}$; followed by 35 cycles of denaturation at $94^{\circ} \mathrm{C}$ for $40 \mathrm{~s}$, annealing at $52^{\circ} \mathrm{C}$ for $40 \mathrm{~s}$, and extension at $72^{\circ} \mathrm{C}$ for $1.5 \mathrm{~min}$; and terminated with a final extension at $72^{\circ} \mathrm{C}$ for $5 \mathrm{~min}$. The 47 isolates that gave no amplifications with the primer pair $137 \mathrm{~S}-\mathrm{F}+137 \mathrm{~S}-\mathrm{R}$ were subjected to PCR amplifications with the four pairs of primers described above, and various types of intron-deletion patterns (Fig. 1, types III, V, and VI cyt b) were observed among

TABLE 2. Polymerase chain reaction (PCR) primers used in this study

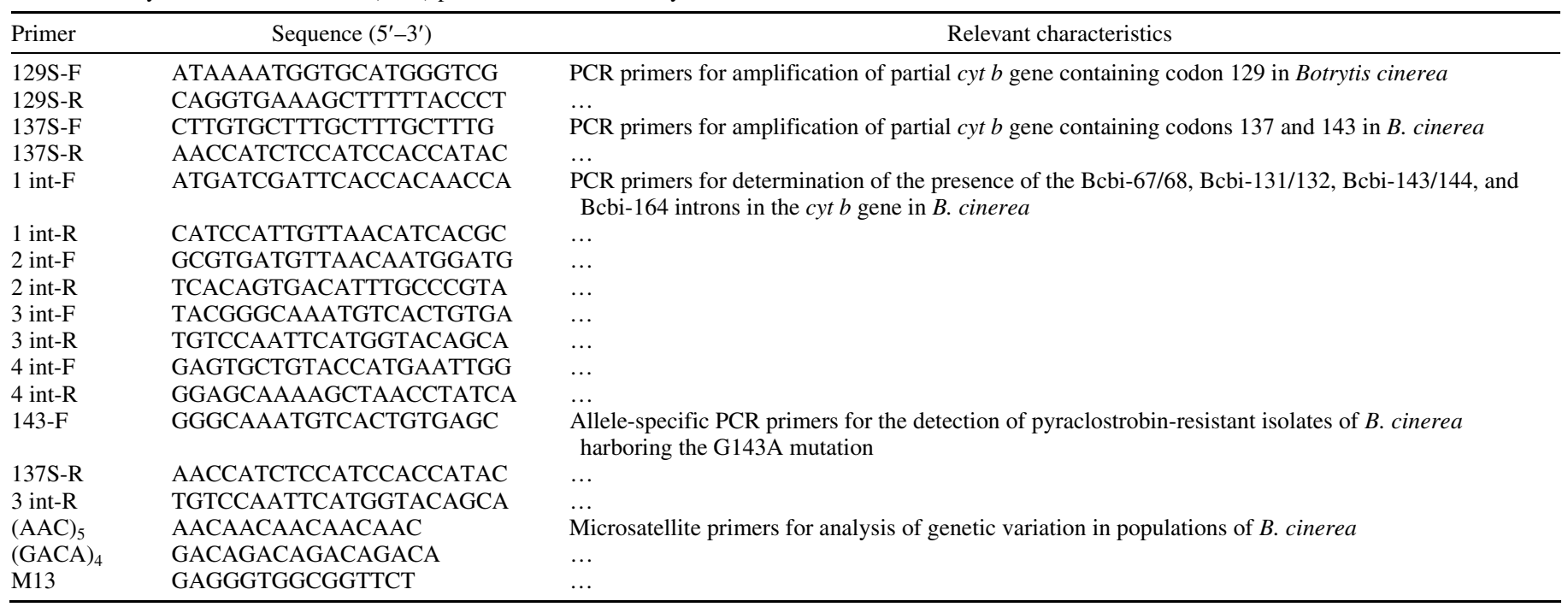


these isolates. As for the other 200 isolates that gave either a 687or 1,892-bp band with the primer pair $137 \mathrm{~S}-\mathrm{F}+137 \mathrm{~S}-\mathrm{R}$, PCR amplification was performed using the primer pair $129 \mathrm{~S}-\mathrm{F}+$ 129S-R (located in the Bcbi-67/68 and Bcbi-131/132 introns, respectively). In total, 199 isolates gave a 1,064-bp fragment, indicating the presence of both the Bcbi-67/68 and Bcbi-131/132 introns, but 1 isolate (isolate 482) gave no product, which produced a $687-b p$ band with primers $137 \mathrm{~S}-\mathrm{F}+137 \mathrm{~S}-\mathrm{R}$. Isolate 482 , again amplified with four pairs of primers $(1$ int- $\mathrm{F}+1$ int- $\mathrm{R}$, 2 int-F +2 int-R, 3 int-F +3 , int- $\mathrm{R}$, and 4 int- $\mathrm{F}+4$ int-R) showed that the Bcbi-67/68 and Bcbi-143/144 introns (type IV $c y t b$ in Fig. 1) were deleted.

We sequenced 6 isolates $(1750,6675,7396,7398,7933$, and 8203) not containing introns Bcbi-143/144 and Bcbi-164 (type III $c y t$ b) with the primer 3 int-F and 4 int-R, 1 isolate (482) not containing introns Bcbi-67/68 and Bcbi-143/144 (type IV cyt $b$ ) with primer pairs 1 int-F +1 int-R and 3 int-F +4 int $\mathrm{R}, 1$ isolate (8292) not containing introns Bcbi-67/68, Bcbi-143/144, and Bcbi-164 (type $\mathrm{V}$ cyt $b$ ) with primer pairs 1 int-F +1 int-R and 3 int-F + 4 int-R, and 16 isolates $(7452,369,370,374,377,455$, 459, 479, 6740, 6741, 6684, 6690, 6696, 6703, 7395, and 7397) containing no introns (type VI cyt $b$ ) with the primer pair 1 int-F +4 int-R (Fig. 1). Sequencing was conducted as described above. There were no differences in amino acids between the isolates sequenced and the sequence of $B$. cinerea deposited at GenBank (accession number AB428335), with the exception of A replacing $\mathrm{G}$ at codon 143 in the PR isolate 7452. Representative sequences were deposited in GenBank under accession numbers JF689848 to JF689851.

Another primer pair, $143-\mathrm{F}+3$ int-R, was designed for detecting the point mutation G143A in $B$. cinerea isolates carrying any type of $c y t b$. The primer pair $143-\mathrm{F}+3$ int-R was expected to generate a 67-bp fragment only from PR isolates containing the point mutation G143A, not from PS isolates. To test specificity of this primer pair, the same isolates and PCR conditions as described for the primer pair 143-F + 137S-R were used.

Genetic relationships among $P R$ and PS isolates as well as isolates carrying different types of $\boldsymbol{c y t} \boldsymbol{b}$. In all, 17 PR (11 from Okanogan and 6 from Columbia Basin) and 51 PS (26 from Okanogan, 9 from Columbia Basin, 7 from Wenatchee, and 9 from Yakima) isolates were analyzed by microsatellite primed-PCR (MP-PCR) with three microsatellite primers: $(\mathrm{AAC})_{5},(\mathrm{GACA})_{4}$, and M13 (Table 2). Of the 68 isolates tested, 13 had type I $c y t b, 32$ had type II $c y t b, 6$ had type III $c y t b, 1$ had type IV cyt $b, 1$ had type $\mathrm{V} c y t b$, and 15 had type VI $c y t b$. These three primers were chosen because they were informative in previous studies on $B$. cinerea $(24,34)$. PCR was conducted with an initial preheat at $95^{\circ} \mathrm{C}$ for $3 \mathrm{~min}$; followed by 40 cycles of denaturation at $94^{\circ} \mathrm{C}$ for $1 \mathrm{~min}$, annealing at $45^{\circ} \mathrm{C}$ for $1 \mathrm{~min}$, and extension at $72^{\circ} \mathrm{C}$ for $1.5 \mathrm{~min}$; and terminated with a final extension at $72^{\circ} \mathrm{C}$ for $7 \mathrm{~min}$. Each isolate was amplified twice separately. The PCR products were separated on $1.2 \%$ agarose gels in $1 \times$ TAE buffer and photographed after staining with ethidium bromide.

To analyze MP-PCR data, each isolate was scored for the presence or absence of each amplicon using the UVP GelDoc-It Imaging System (Ultra Violet Products). Genetic similarities (S) were calculated using simple matching coefficient. A phenogram was constructed using the unweighted pair group method with arithmetic average (UPGMA) by the program SAHN (sequential, agglomerative, hierarchical, and nested) clustering methods of the software package NTSYS-pc 2.1 (Department of Ecology and Evolution, State University of New York).

\section{RESULTS}

Frequency of pyraclostrobin resistance in apple orchards. Among the 220 isolates collected from the five apple orchards where the pyraclostrobin-containing fungicide Pristine had been used for four consecutive years, 43 isolates $(19.5 \%)$ were resistant to pyraclostobin. Resistance frequency in these five orchards was 11.3 to $37.3 \%$.

The 43 PR isolates from these five apple orchards and the 30 additional PR isolates obtained from decayed apple fruit obtained from a fruit packinghouse all had RF $>900$, indicating that they were highly resistant to pyraclostrobin.

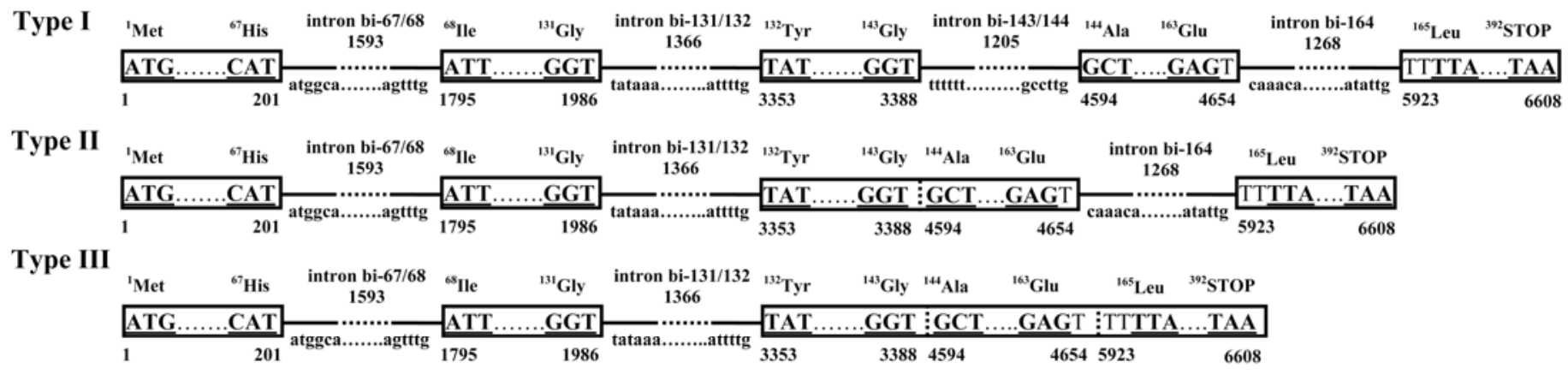

\begin{tabular}{|c|c|c|c|c|c|c|c|c|c|c|c|c|}
\hline Type IV & ${ }^{1}$ Met & ${ }^{67} \mathrm{His}$ & ${ }^{68} \mathrm{Ile}$ & ${ }^{131}$ Gly & $\begin{array}{c}\text { intron bi-131/132 } \\
1366\end{array}$ & ${ }^{132} \mathrm{Tyr}$ & ${ }^{143}$ Gly & ${ }^{144} \mathrm{Ala}$ & ${ }^{163}$ Glu & $\begin{array}{c}\text { intron bi-164 } \\
1268\end{array}$ & ${ }^{165}$ Leu & ${ }^{392}$ STOP \\
\hline
\end{tabular}

\begin{tabular}{|c|c|c|c|c|c|c|c|c|c|c|c|}
\hline \multirow[t]{3}{*}{ Type V } & ${ }^{1}$ Met & ${ }^{67} \mathrm{His}$ & ${ }^{68} \mathrm{Ile}$ & ${ }^{131}$ Gly & \multirow{2}{*}{$\begin{array}{c}\text { intron bi-131/132 } \\
1366 \\
\end{array}$} & \multirow{2}{*}{$\begin{array}{r}{ }^{132} \mathbf{T y r} \\
\text { TAT }\end{array}$} & ${ }^{143}$ Gly & ${ }^{144} \mathrm{Ala}$ & ${ }^{16.3}$ Glu & ${ }^{165}$ Leu & ${ }^{392}$ STOP \\
\hline & ATQ & CAT & $\mathbf{A T}$ & .GGT & & & GGT & :GCI & .GAC & TTT & $\ldots$ TAA \\
\hline & 1 & 20 & 1795 & 1986 & $\cdots$ & 3353 & 3388 & 84594 & 46 & 5923 & 6608 \\
\hline
\end{tabular}

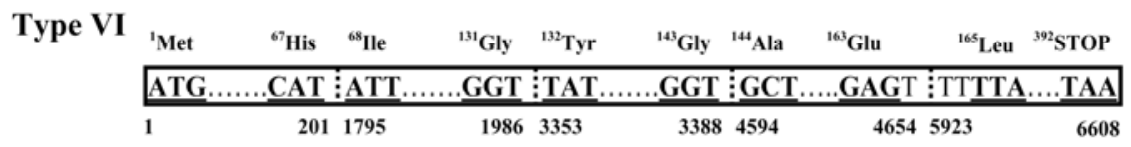

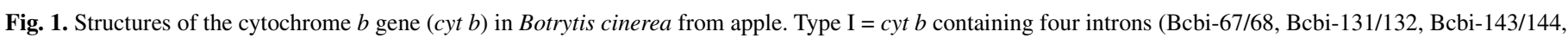

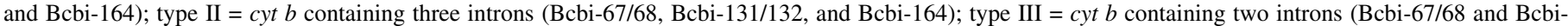

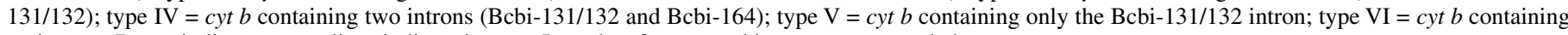
no introns. Boxes indicate exons; lines indicate introns. Lengths of exons and introns are not scaled. 
Sequence comparison and molecular detection of the G143A mutation in $\boldsymbol{c y t} \boldsymbol{b}$ in $\boldsymbol{B}$. cinerea. Five PR (8003, 8178, 8080,8220 , and 8134) and five PS $(6629,8018,8147,8210$, and 8246 ) isolates were sequenced with the primer pair of $137 \mathrm{~S}-\mathrm{F}+$ 137S-R. All five PS isolates had the sequence of GGT at the codon position 143 of $c y t b$ but this codon was replaced by GCT in all five PR isolates. Except for this point mutation, all 10 isolates analyzed had identical deduced amino acid sequences in the other sequenced part of $c y t b$.

All 73 PR and 50 PS isolates were amplified with primer pairs of $143-\mathrm{F}+137 \mathrm{~S}-\mathrm{R}$ and $143-\mathrm{F}+3$ int-R. The allele-specific PCR analysis with these two primer pairs showed that $72 \mathrm{PR}$ isolates gave both expected 262- and 67-bp bands. One PR isolate (7452) produced no amplification with the primer pair $143-\mathrm{F}+137 \mathrm{~S}-\mathrm{R}$ but the expected 67-bp fragment was amplified from this isolate using the primer pair $143-\mathrm{F}+3$ int-R. No amplifications were observed from the 50 PS isolates tested. The results indicated that all 73 PR isolates harbored the same point mutation, G143A.

Gene structure of cyt $\boldsymbol{b}$ in $B$. cinerea isolates from apple. Among 247 B. cinerea isolates tested, there were six types (I to VI) of $c y t b$ (Fig. 1; Table 1). In total, 23 (9.3\%) isolates had type I $c y t b$ gene containing all four introns (Bcbi-67/68, Bcbi131/132, Bcbi-143/144, and Bcbi-164), 176 (71.3\%) isolates had type II $c y t b$ gene containing three introns (Bcbi-67/68, Bcbi131/132, and Bcbi-164), 6 (2.4\%) isolates (1750, 6675, 7396, 7398,7933 , and 8203) had type III $c y t$ b gene containing two introns (Bcbi-67/68 and Bcbi-131/132), 1 (0.4\%) isolate (482) had type IV cyt $b$ gene containing two introns (Bcbi-131/132 and Bcbi-164), 1 (0.4\%) isolate (8292) had type V cyt b gene containing only the Bcbi131/132 intron, and 40 (16.2\%) isolates had type VI $c y t b$ gene containing no introns.

Of the 73 PR isolates, $72(98.6 \%)$ had type II $c y t b$ gene and 1 isolate (7452) had type VI cyt $b$ gene. All 73 PR isolates did not contain the Bcbi-143/144 intron. Of the total 174 PS isolates, only $23(13.2 \%)$ contained the Bcbi-143/144 intron. Among the PS isolates from the Okanogan, Columbia Basin, Wenatchee, and Yakima areas, the frequency of isolates containing the Bcbi$143 / 144$ intron was $14.8,5.1,13.6$, and $20.0 \%$, respectively (Table 1).

Genetic relationships among $P R$ and $P S$ isolates, and isolates carrying different types of $\boldsymbol{c y t} \boldsymbol{b}$. Three microsatellite primers generated a total of 34 polymorphic fragments from $68 \mathrm{~B}$. cinerea isolates. Examples of DNA fingerprint patterns generated by the primer $(\mathrm{AAC})_{5}$ are presented in Figure 2. UPGMA analysis showed that $17 \mathrm{PR}$ isolates were clustered into different groups (Fig. 3). One PR isolate (7452) grouped together with other 14 PS isolates, which all had type VI $c y t b$. In all, 51 isolates, including 13,32 , and 6 having types I, II, and III cyt $b$, respectively, were also clustered into different groups, but 15 isolates having type VI $c y t b$ were grouped together and separated from those having type I, II, III, IV, or V cyt b (Fig. 3). These results indicated that PR isolates originated from different lineages, and there was no specific correlation between $c y t b$ type (I, II, and III) and the genetic background of the isolates; however, isolates carrying type VI $c y t b$ might have originated from the same lineage.

\section{DISCUSSION}

In the present study, we investigated the molecular mechanisms conferring resistance to the QoI fungicide pyraclostrobin and analyzed the structure of the cyt $b$ gene in B. cinerea populations from apple. One of the major findings of this study was that we documented the presence of various intron-deletion patterns in the $c y t b$ gene in $B$. cinerea. We reported six types of the $c y t b$ gene in B. cinerea populations from apple. Among the six types of $c y t b$, type I, containing four introns (introns Bcbi-67/68, Bcbi-131/132, Bcbi-143/144, and Bcbi-164), and type II, containing three introns (introns Bcbi-67/68, Bcbi-131/132, and Bcbi-164), were the same as previously reported in $B$. cinerea $(1,16)$. To our knowledge, this is the first report of the four additional deletion patterns of mitochondrial introns in $c y t b$ in $B$. cinerea. These findings suggest that $B$. cinerea isolates carrying different types of $c y t b$ were present in the pathogen populations from apple in Washington State and that isolates carrying type II $c y t b$ were predominant.

In this study, we found that $\approx 20 \%$ of $B$. cinerea isolates collected from five apple orchards where the pyraclostrobin-containing fungicide Pristine had been used in each of four consecutive years were resistant to pyraclostrobin. In eastern Washington State, apple is grown in a semiarid climate. Only a limited number of fungicide applications may be used in apple orchards because apple scab caused by Venturia inaequalis is not a major production problem and powdery mildew caused by Podosphaera leucotricha is the only major disease that fungicides may be used to control it in the region (17,31). In the five apple orchards sampled in this study, when QoIs were used in early growing seasons, only one to two sprays of QoI fungicides might be applied for control of powdery mildew each season. Given the fact that only one application of Pristine was used per season and the use of other QoIs was limited in these orchards, our results suggest that the risk for development of resistance to pyraclsotrobin in B. cinerea is high.

In our study, isolates were classified as either sensitive or resistant to pyraclostrobin in a mycelial growth assay (18). The phenotypes of the isolates determined in the mycelial growth assay were in agreement with the results of the molecular analysis of the point mutation G143A in $c y t b$ because G143A was observed in all PR isolates but not PS isolates. Thus, the molecular analysis results support the recommendation that the mycelial growth assay on PDA at the discriminatory concentration of pyraclostrobin of $5 \mu \mathrm{l} / \mathrm{ml}$ is a reliable method for phenotyping isolates for resistance to pyraclostrobin (18). Furthermore, we developed an allele-specific PCR assay for detection of the point mutation G143A in B. cinerea isolates varying in the cyt $b$ gene structure (type I to VI). The developed assay would facilitate QoI-resistance monitoring efforts.

Many mitochondrial intronic mutants can revert frequently by clean deletion of the mutated intron, a process requiring the involvement of mitochondrial reverse transcriptase activity mediated by the intron-encoded protein (11). Intron-deletion had been found in revertants of mitochondrial intronic mutants of Sac-

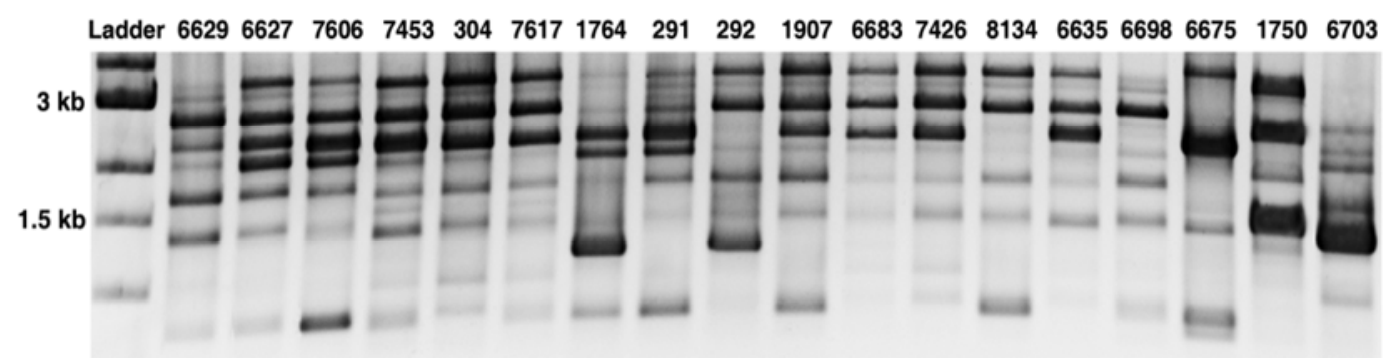

Fig. 2. Electrophoretic separation of DNA fingerprints of Botrytis cinerea amplified by the microsatellite primer (AAC)5. 
charomyces cerevisiae and $S$. pombe (11). The study on $P$. anserina showed that DNA deletion of mitochondrial introns may be involved in the process of senescence (29). Both senescent and young cultures of $P$. anserina contained DNA molecules precisely deleted for intronic sequences but these deletions were observed to a much greater extent in senescent than in young cultures (29). More research is needed to understand the mechanisms of intron deletion, the function of various intron-deletion patterns in $c y t b$, and the relationships of types of intron-deletion and QoI resistance in $B$. cinerea and other important plant fungal pathogens.

Group I introns common in fungi are self-splicing RNAs. Splice site recognition is dependent on an internal guide sequence of the intron, which pairs with the exonic sequences flanking the $5^{\prime}$ splice site. Therefore, the exonic sequence close to the splice junctions plays an essential role in mRNA splicing $(5,21)$. It has been documented in many rust fungi, some Agrocybe spp., A. solani, and Pyrenophora teres that the presence of the intron directly located after codon 143 prevents the development of point mutation G143A $(13,25,28,30)$. In our study, none of the 73 PR isolates carried the Bcbi-143/144 intron, and our results were in agreement with those of previous studies on $B$. cinerea from grape, strawberry, and vegetables $(1,16,23)$. In the present study, $>90 \%$ of the isolates $(224 / 247)$ of $B$. cinerea from various appleproduction districts in Washington State did not carry the Bcbi143/144 intron, suggesting that B. cinerea populations from apple pose a high inherent risk for the development of resistance to QoI. A high percentage of isolates $(>76 \%)$ not harboring the Bcbi143/144 intron in cyt $b$ also was observed in $B$. cinerea populations from grape in France, but only $\approx 40$ to $60 \%$ of the $B$. cinerea isolates from various hosts in Japan lacked the Bcbi143/

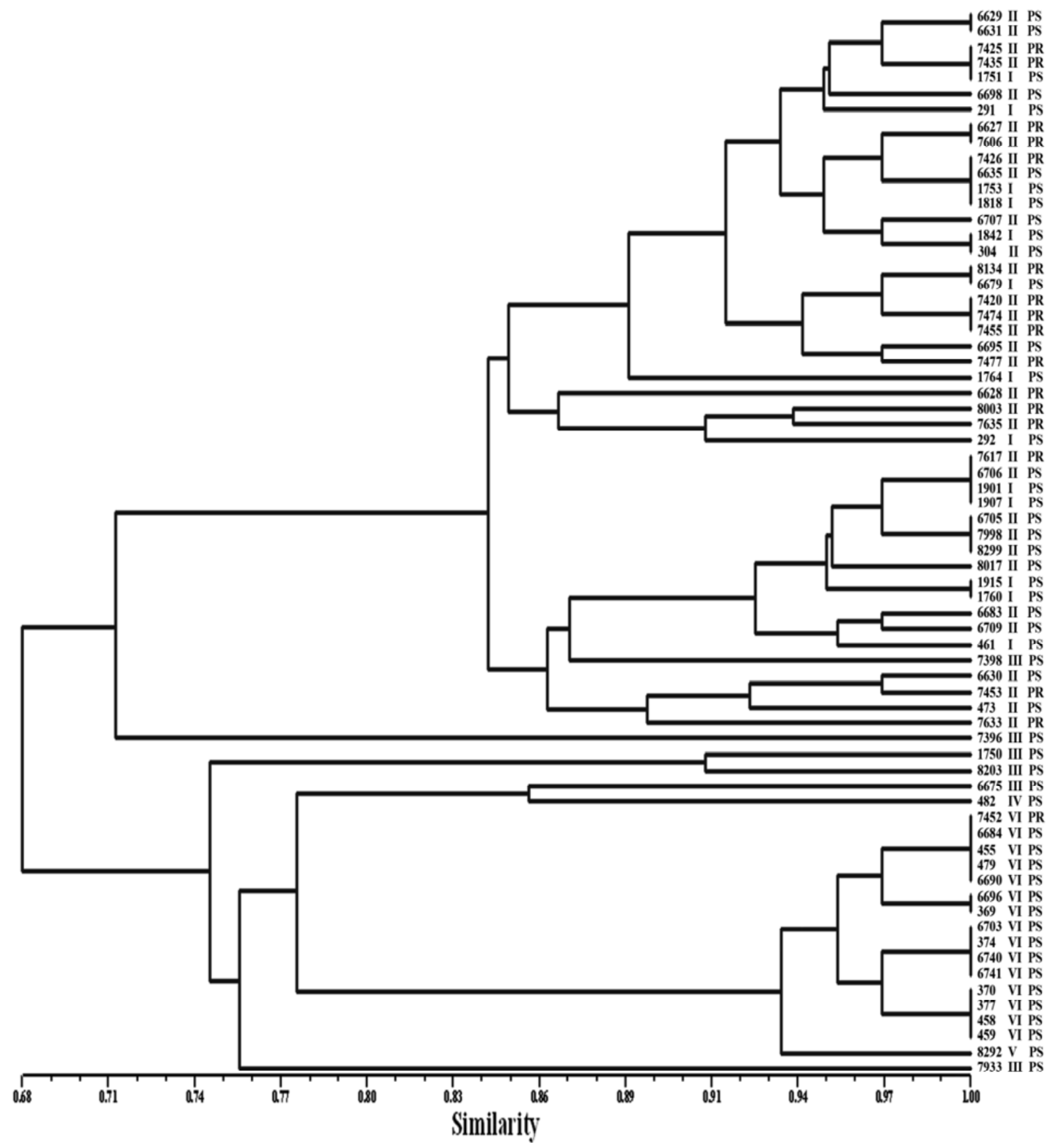

Fig. 3. Unweighted pair group method with arithmetic average cluster analysis of microsatellite-primed polymerase chain reaction data for 68 Botrytis cinerea isolates from apple, including 17 pyraclostobin-resistant (PR) and 51 pyraclostrobin-sensitive (PS) isolates (13 carrying type I cyt $b, 32$ carrying type II $c y t b, 6$ carrying type III cyt $b, 1$ carrying type IV cyt $b, 1$ carrying type V cyt $b$, and 15 carrying type VI $c y t b$ ). 
144 intron in $c y t b$ (1). It appears that the frequency of isolates lacking the Bcbi-143/144 intron in cyt $b$ in $B$. cinerea populations may vary with hosts or geographic regions.

In a previous study on the fitness of pyraclostrobin resistance in $B$. cinerea from apple, pyraclostrobin resistance was stable in the absence of the fungicide and resistance to pyraclostrobin did not significantly impair individual fitness components. However, PR isolates of $B$. cinerea from apple exhibited competitive disadvantage over a PS isolate on apple fruit (19). Of the six types of $c y t b$ in $B$. cinerea documented in the present study, isolates carrying types III, IV, and V cyt $b$ were present at a much lower frequency than the other types. It remains to be determined whether the low frequency of isolates carrying types III, IV, and V cyt $b$ is associated with fitness costs of these isolates because no isolates from these groups were included in the fitness study (19).

In previous studies, allele-specific PCR (16) and hybridization probe (1) assays were developed for detection of the point mutation G143A in B. cinerea. Because the reverse primer BcAR$\mathrm{R}$ in the allele-specific PCR assay developed by Jiang et al. (16) was distributed in the Bcbi-164 intron, this assay is not able to detect the point mutation G143A in $B$. cinerea isolates lacking the Bcbi-164 intron, as happened to the allele-specific primers 143-F $+137 \mathrm{~S}-\mathrm{R}$ developed in the present study. Similarly, the forward primer Bccytb-HPF1 in the hybridization probe assay developed by Banno et al. (1) was located in the Bcbi-131/132 intron; thus, this assay is not able to detect the point mutation G143A in $B$. cinerea isolates without the Bcbi-131/132 intron in $c y t b$. More recently, Leroux et al. (23) develop a cleavable amplified polymorphic sequences (CAPS) assay for detection of the G143A mutation in $B$. cinerea from grape from France. The CAPS assay is not able to detect the G143A point mutation in $B$. cinerea isolates carrying type III, V, or VI $c y t b$ because the two primers QoI3ext and QoI4ext used in the assay were located in the introns Bcbi-131/132 and Bcbi-164, respectively. In addition, the digestion site for the restriction enzyme used in the CAPS assay only exists in $B$. cinerea isolates containing the G143A point mutation. In our study, the primer pair $143-\mathrm{F}+3$ int- $\mathrm{R}$ was designed based only on the sequence of exons. It can solve the problems encountered in the three previously published assays and, thus, is able to detect the point mutation G143A in B. cinerea isolates harboring a varying number of introns in $c y t b$, as we reported in this study.

A high level of genetic variation in populations of $B$. cinerea from apple in Washington State was observed based on the MPPCR analysis. Our results were consistent with previous studies on genetic structure analysis of $B$. cinerea from various crops $(24,26)$. Analysis of genetic background showed that PR isolates originated from different lineages, suggesting that these different genotypes in $B$. cinerea populations pose risk for the development of QoI resistance. For $B$. cinerea isolates carrying type I to III $c y t$ $b$, it appeared that there was no specific correlation between the type of $c y t b$ and the genetic background of the isolates. However, 15 isolates harboring type VI $c y t b$ apparently had a very similar genetic background, suggesting that these 15 isolates may originate from the same lineage but evolved small variation during their evolution. In this study, we had only one isolate each carrying type IV and V cyt $b$, and more isolates would be needed to test genetic relationships between those carrying type IV and $\mathrm{V} c y t b$ and those carrying other types of $c y t b$.

In summary, in this study we reported six types of $c y t b$ present in the $B$. cinerea populations from apple in Washington State and the point mutation $\mathrm{G} 143 \mathrm{~A}$ correlating with pyraclostrobin resistance in field isolates of $B$. cinerea from apple. Based on the patterns of intron-deletion in $c y t b$, we developed an allelespecific PCR assay for the detection of the point mutation G143A in $B$. cinerea isolates regardless of the type of $c y t b$ the isolates carried. This is the first report of the complete deletion of introns in the $c y t b$ gene in $B$. cinerea. The information presented in this study would provide new insights regarding the study of QoI resistance in plant fungal pathogens.

\section{ACKNOWLEDGMENTS}

This research was supported, in part, by the Washington Tree Fruit Research Commission. This manuscript is Plant Pathology New Series 0579, Department of Plant Pathology, College of Agricultural, Human, and Natural Resource Sciences Agricultural Research Center, Project Number WNP00367, Washington State University, Pullman 99164-6430. We thank Z. Ma for review of the manuscript.

\section{LITERATURE CITED}

1. Banno, S., Yamashita, K., Fukumori, F., Okada, K., Uekusa, H., Takagaki, M., Kimura, M., and Fujimura, M. 2009. Characterization of QoI resistance in Botrytis cinerea and identification of two types of mitochondrial cytochrome $b$ gene. Plant Pathol. 58:120-129.

2. Bartlett, D. W., Clough, J. M., Godwin, J. R., Hall, A. A., Hamer, M., and Parr-Dobrzanski, B. 2002. The strobilurin fungicides. Pest Manage. Sci. 58:649-662.

3. Brent, K. J., and Hollomon, D. W. 1998. Fungicide resistance: The assessment of risk. FRAC Monogr. No. 2. Global Crop Protection Federation, Brussels

4. Cech, T. R. 1988. Conserved sequences and structures of group I introns: Building an active site for RNA catalysis-a review. Gene 73:259-271.

5. Chatterjee, P., Brady, K. L., Solem, A., Ho, Y., and Caprara, M. G. 2003. Functionally distinct nucleic acid binding sites for a group I intron encoded RNA maturase/DNA homing endonuclease. J. Mol. Biol. 329:239-251.

6. Fernández-Ortuño, D., Torés, J. A., de Vicente, A., and Pérez-García, A. 2008. Mechanisms of resistance to QoI fungicides in phytopathogenic fungi. Int. Microbiol. 11:1-9.

7. Fisher, N., and Meunier, B. 2008. Molecular basis of resistance to cytochrome $b c_{l}$ inhibitors. FEMS Yeast Res. 8:183-192.

8. Fungicide Resistance Action Committee. 2011. FRAC Code List: Fungicides sorted by mode of action (including FRAC Code numbering). http://www.frac.info.

9. Fungicide Resistance Action Committee. 2011. List of pathogens with field resistance towards QoI fungicides. http://www.frac.info.

10. Fungicide Resistance Action Committee. 2011. Mutations associated with QoI resistance. http://www.frac.info.

11. Gargouri, A. 2005. The reverse transcriptase encoded by ail intron is active in trans in the retro-deletion of yeast mitochondrial introns. FEMS Yeast Res. 5:813-822.

12. Gisi, U., Sierotzki, H., Cook, A., and McCaffery, A. 2002. Mechanisms influencing the evolution of resistance to Qo inhibitor fungicides. Pest Manage. Sci. 58:859-867.

13. Grasso, V., Palermo, S., Sierotzki, H., Garibaldi, A., and Gisi, U. 2006. Cytochrome $b$ gene structure and consequences for resistance to Qo inhibitor fungicides in plant pathogens. Pest Manage. Sci. 62:465-472.

14. Ishii, H., Fountaine, J., Chung, W. H., Kansako, M., Nishimura, K., Takahashi, K., and Oshima, M. 2009. Characterization of QoI-resistant field isolates of Botrytis cinerea from citrus and strawberry. Pest Manage. Sci. 65:916-922

15. Jarvis, W. R. 1977. Botryotinia and Botrytis Species: Taxonomy, Physiology and Pathogenicity. Monograph 15. Research Branch Canada, Department of Agriculture, Ottawa, Ontario, Canada.

16. Jiang, J. H., Ding, L. S., Michailides, T. J., Li, H. Y., and Ma, Z. H. 2009. Molecular characterization of field azoxystrobin-resistant isolates of Botrytis cinerea. Pestic. Biochem. Physiol. 93:72-76.

17. Jones, A. L., and Aldwinckle, H.S., ed. 1990. Compendium of Apple and Pear Diseases. American Phytopathological Society, St. Paul, MN.

18. Kim, Y. K., and Xiao, C. L. 2010. Resistance to pyraclostrobin and boscalid in populations of Botrytis cinerea from stored apples in Washington State. Plant Dis. 94:604-612.

19. Kim, Y. K., and Xiao, C. L. 2011. Stability and fitness of pyraclostrobinand boscalid-resistant phenotypes in field isolates of Botrytis cinerea from apple. Phytopathology 101:1385-1391.

20. Kim, Y. S., Dixon, P., Vincelli, P., and Farman, M. L. 2003. Field resistance to strobilurin $(\mathrm{QoI})$ fungicides in Pyricularia grisea caused by mutations in the mitochondrial cytochrome $b$ gene. Phytopathology 93:891-900.

21. Lambowitz, A. L., and Belfort, M. 1993. Introns as mobile genetic elements. Annu. Rev. Biochem. 62:587-622.

22. Leroux, L. 2004. Chemical control of Botrytis and its resistance to chemical fungicides. Pages 195-222 in: Botrytis: Biology, Pathology and Control. Y. Elad, B. Williamson, P. Tudzynski, and N. Delen, eds. Kluwer 
Academic Publishers, Dordrecht, The Netherlands.

23. Leroux, P., Gredt, M., Leroch, M., and Walker, A. 2010. Exploring mechanisms of resistance to respiratory inhibitors in field strains of Botrytis cinerea, the causal agent of gray mold. Appl. Environ. Microbiol. 76:6615-6630.

24. Ma, Z., and Michailides, T. J. 2005. Genetic population structure of Botrytis cinerea from different hosts in California. Plant Dis. 89:10831089.

25. Mouhamadou, B., Ferandon, C., Barroso, G., and Labarere, J. 2006. The mitochondrial apocytochrome b genes of two Agrocybe species suggest lateral transfers of group I homing introns among phylogenetically distant fungi. Fungal Genet. Biol. 43:135-145.

26. Muňoz, G., Hinrichsen, P., Brygoo, Y., and Griaud, T. 2002. Genetic characterization of Botrytis cinerea populations in Chile. Mycol. Res. 106:594-601.

27. Olaya, G., and Köller, W. 1999. Diversity of kresoxim-methyl sensitivities in baseline populations of Venturia inaequalis. Pestic. Sci. 55:1083-1088.

28. Rosenzweig, N., Olaya, G., Atallah, Z. K., Cleere, S., Stanger, C., and Stevenson, W. R. 2008. Monitoring and tracking changes in sensitivity to azoxystrobin fungicide in Alternaria solani in Wisconsin. Plant Dis. 92:555-560.
29. Sainsard-Chanet, A., Begel, O., and Belcour, L. 1993. DNA deletion of mitochondrial introns is correlated with the process of senescence in Podospora anserina. J. Mol. Biol. 234:1-7.

30. Sierotzki, H., Frey, R., Wullschleger, J., Palermo, S., Karlin, S., Godwin, J., and Gisi, U. 2007. Cytochrome $b$ gene sequence and structure of Pyrenophora teres and $P$. triticirepentis and implications for QoI resistance. Pest Manage. Sci. 63:225-233.

31. Smith, T. J., Dunley, J., Beers, E. H., Brunner, J. F., Grove, G. G., Xiao, C. L., Elfving, D. C., Peryea, F., Parker, R., Maver, D. F., Woodruff, R., Daniels, C., Maxwell, T., and Roberts, S. 2007. 2007 Crop Protection Guide for Tree Fruits in Washington (EB 0419).

32. Torriani, S. F., Linde, C. C., and McDonald, B. A. 2009. Sequence conservation in the mitochondrial cytochrome $b$ gene and lack of G143A QoI resistance allele in a global sample of Rhynchosporium secalis. Aust. Plant Pathol. 38:202-207.

33. Xiao, C. L., and Boal, R. J. 2009. Preharvest application of a boscalid and pyraclostrobin mixture to control postharvest gray mold and blue mold in apples. Plant Dis. 93:185-189.

34. Yin, Y. N., Kim, Y. K., and Xiao, C. L. 2011. Molecular characterization of boscalid resistance in field isolates of Botrytis cinerea from apple. Phytopathology 101:986-995. 